\title{
Research on the Performance Factors and Mechanism of Postgraduate Joint Training in the Mode of Graduate Workstation
}

\author{
Lin $\mathrm{Li}^{\mathrm{a}}$, Ya-bin $\mathrm{Li}^{\mathrm{b}}$ and Tie-jun $\mathrm{Ci}^{\mathrm{c}}$ \\ Department of Mechanical Engineering, North China Electric Power University, Baoding, China \\ alzx615@126.com, blybhnjz@163.com, ${ }^{c} c t j 920 @ 126 . c o m$
}

Keywords: Graduate Workstation, Joint Training, Training Performance, Mechanism

\begin{abstract}
Graduate joint training workstation is the bridge and link of industry-university-research cooperative education and the workstation mode is a kind of educational model combining theoretical study with practical activities to improve students' comprehensive ability, which conforms to the inherent law of educational development and its contribution to personnel training has been more and more widely concerned by society. In order to provide theoretical help for the better construction of graduate workstation, this paper focuses on the performance factors of postgraduate joint training in workstation mode, and the mechanism of each factor is deeply analyzed.
\end{abstract}

\section{Introduction}

Graduate workstation is a technical research and development institution which is established by the enterprise or scientific research units and is composed of college tutors, graduate team and the R \& $\mathrm{D}$ team outside. Also, the graduate workstation is a platform for industry-university-research cooperative education and an important innovation practice base for college graduate training [1]. This definition clearly defines the basic functions of the graduate workstation: technical research and development and personnel training. The basic attributes of graduate workstation is the R \& D alliance carrier and cooperation bridge between enterprise and college. Anping Li and others think that enterprise graduate workstation is a personnel training mode which is based on the industry-university-research and has a positive role in promoting the enterprise innovation [2]. Jinrong Shen and others think that the establishment of graduate workstation has found the similar result as the United States "university industry cooperative research program" [3].

The rapid development of the graduate workstation shows the characteristics which are significantly different from other school enterprise cooperation modes. Taking the graduate workstation as the research object, this paper analyzed the performance factors and mechanism of postgraduate joint training in the mode of graduate workstation and hopes to provide theoretical help for the construction of graduate workstation.

\section{Analysis on Performance Factors of Postgraduate Joint Training}

For colleges and universities, the talent training is their basic responsibility and central task, and school enterprise the school-enterprise cooperation is the expansion of this function. Talent training is guided by tutor to improve graduate practical ability, application ability, professional ability. There is knowledge potential difference between college knowledge and enterprise application knowledge. So, there is a need to carry out school-enterprise cooperation. For enterprises, personnel training is a by-product of developing school enterprise cooperation and improving their R \& D capability. Personnel training is conducive to improve absorptive capacity and innovation performance, help to maintain competitive advantage, conducive to long-term development of enterprises.

Through the above analysis, the performance factors of postgraduate joint training are jointly determined by graduate students' own factors, college factors and enterprise factors. According to the actual situation, the performance factors of postgraduate joint training in the mode of graduate workstation can be summarized as follows: the overall knowledge of colleges and universities, 
university instructors and team guidance, enterprise $\mathrm{R} \& \mathrm{D}$ activities tutor and workstation environment.

In order to analyze the mechanism of each influencing factor, take the performance of postgraduate joint training as the dependent variable and take the influencing factors as the independent variable, put forward the following hypothesis:

H1: The overall knowledge of colleges and universities is positively correlated with talent training performance.

H2: The college tutors and team guidance are positively correlated with talent training performance.

H3: The enterprise $\mathrm{R} \& \mathrm{D}$ activities tutors are positively correlated with talent training performance.

H4: The workstation environment is positively correlated with talent training performance.

\section{Mechanism of Performance Factors}

The Overall Knowledge of Colleges and Universities. Knowledge potential difference is the inevitable result of the pursuit of certain technical ability for the realization of certain output expectations, which determines the probability that certain subjects choose a cooperative way to gain the ability to succeed and is the key to effective use of old knowledge and fuse new knowledge[4]. Based on the classification of knowledge and ability, scholars expand the concept of knowledge potential difference. The unbalanced phenomenon of technical capability distribution in specific cluster is defined by the potential difference of technical ability. The existence of this phenomenon depends on the subject's learning process of the new knowledge outside the cluster [5].The subjects have different knowledge potential because of the obvious difference in quantity and quality of knowledge[6]. Graduate choice universities often based on the comparison of knowledge potential difference and technical ability potential difference. The graduate often focus on the schools which is in the position of high knowledge potential, with well academic reputation, knowledge reserves and research potential. Similarly, enterprises choose cooperative universities are often based on the ability of basic research and even applied research. From the perspective of personnel training, graduate students relative to colleges and universities have obvious knowledge potential difference. So, knowledge exploration is their main purpose regardless of the complex enrollment motivation. Therefore, the overall knowledge of colleges and universities is one of the factors affecting the performance of personnel training in the graduate workstation.

The College Tutors and Team Guidance. The cultivation of graduate students in colleges and universities is an independent learning process that takes the overall knowledge of colleges as the atmosphere and is guided directly by the tutor of related subjects, and the tutor is the first responsible person of postgraduate training. Graduate learning effect is based on knowledge absorptive capacity which includes knowledge identification and knowledge digestion ability and is developed from the relationship partners [7]. The guidance of relevant discipline instructors is the premise and the main way to absorb, digest and apply graduate knowledge.

Knowledge can be divided into two categories: tacit knowledge and explicit knowledge[8]. The tacit knowledge includes personal experiences, feelings, beliefs, modes of thinking and skills, which can not be directly expressed in words. The explicit knowledge is one kind of text knowledge which can be applied to communicate available standard and scientific language. There are four basic patterns of conversion between the tacit knowledge and explicit knowledge, which is called SECI that includes subtle, external express, summary combination and internal sublimation [9], and the process of knowledge transformation is the process of knowledge creation. Therefore, from the tutor, the graduate not only get the explicit knowledge which is showed by the papers and the patents, but also the tacit knowledge which is reflected by the scientific research methods, encoding methods, academic norms and academic accomplishment in the process of interaction between teachers and students. To some extent, tacit knowledge is more important to the innovation level and ability of graduate students. At the same time, postgraduate learning is a collective learning process and the graduate student team learning under tutor is more cross, complementary. Graduate students have 
their own research direction, independent and interrelated with each other, and the jointly improve needs knowledge sharing, communication. The team guidance is especially obvious between the doctors and masters, senior graduate students and low grade graduate students. Therefore, the college tutors and team guidance are another influential factor in the personnel training of graduate workstation.

The Enterprise R \& D Activities Tutors. From the perspective of knowledge potential difference, there are also potential differences between graduate students and enterprises. The technical knowledge, practical knowledge, professional skill, application ability and innovation ability of graduate students are obviously different from those of enterprises. The graduate workstation is one kind of reform of talent training mode, which is based on the knowledge potential difference. The theory of absorptive capacity holds that the knowledge that the "students" get from the "teachers" shows great difference because of the external knowledge sources [10-12].The knowledge of college teachers shows more basic research strength, but the enterprise tutors are the main body of enterprise research and development and their rich practical knowledge, technology research and development experience and a high degree of market sensitivity is not available to college tutors.

The ability, level and intensity of R \& D activities of enterprises are the embodiment of their own explicit absorptive capacity, which is helpful to improve the discrimination of external knowledge and the ability and level of knowledge acquisition, digestion and utilization[13]. R \& D activities help to create new knowledge or knowledge portfolio, increase the stock of knowledge, thereby affect innovation[14]. Except for the direct interface to train the students, it is more important for graduate students to actively participate in the leading enterprise technology R \& D activities, in which learning experience, practical knowledge and improve enterprise technology $\mathrm{R}$ \& D capability, which is the enterprise graduate workstation goal in. Based on the above analysis, the enterprise $\mathrm{R} \& \mathrm{D}$ activities tutors are one of the factors affecting the personnel training of the graduate workstation.

The Workstation Environment. The workstation environment is created by enterprise to meet the work situation and their own cultural identity. The workstation environment is also helpful for the postgraduate to accept the enterprise and join in the enterprise activities from psychological as soon as possible, so as to better carry out scientific research and technological development. Workstation environmental factors include whether to establish a good incentive system, whether the allocation of adequate human resources, whether invested enough financial, organizational and logistical resources and other variables[15-16]. The good workstation environment is an important guarantee for introducing the college knowledge into enterprise and the living and learning of postgraduate in the workstation, which embodies the educational environment. School-enterprise and the workstation environment are closely linked[17]. Thus, workstation environment is also one of the factors affecting talent training performance.

\section{Conclusion and Prospect}

This paper studied the performance factors of postgraduate joint training in the mode of graduate workstation and found that the overall knowledge of colleges and universities, university instructors and team guidance, enterprise R \& D activities tutor and workstation environment are the main factors affect joint training performance of postgraduate. Through the study of the mechanism of each performance influencing factors, we can find that the largest value of the joint training of the postgraduate needs the joint efforts of the colleges and universities, enterprises and the graduate students. The interaction mechanism among the performance factors is the next key research direction. 


\section{Acknowledgements}

This research is supported by the Fundamental Research Funds for the Central Universities (2016MS113)

\section{Reference}

[1] Zhu Guanghua, Chen Wanming, Cai Ruilin. Study on absorptive capacity variable co-evolution mechanism of the enterprise innovation performance [J]. Science and Technology Management Research, 2016, 36(2):130-138.

[2] Li Anping, Chen Zhidong, Pan Jianbo, et al. The construction of collaborative postgraduate training mode based on the combination of industry, University and research [J]. China Adult Education, 2010(2):88-90.

[3] Shen Jinrong, Lei Kai. Research on Problems and Countermeasures of graduate workstation in Chinese Enterprises [J]. Journal of Nanjing University of Science and Technology, 2011(5):92-96.

[4] Griliches Z. Patents and Productivity[M]. Chicago: University of Chicago Press, 1984:204-220.

[5] Wei Jiang. Industrial cluster- innovation system and technology learning [J]. Beijing: Science Press, 2003:78-81.

[6] Du Jing, Wei Jiang. An analysis of growth theory of knowledge stock [J]. Science of Science and Management of S.\& T, 2004(1):24-27.

[7] Dyer J H, Singh H. The Relational View: Cooperative Strategy and Sources of Interorganizational Competitive Advantage [J]. Academy of Management Review, 1998, 23(4):660-679.

[8] Takeuchi, Hirotaka. The knowledge-creating company :[M]. Oxford University Press, 1995.

[9] Leonard-Barton D. Wellsprings of Knowledge: Building and Sustaining the Sources of Innovation [M]. Harvard Business School Press, 1995.

[10] Belderbos R, Carree M, Lokshin B. Cooperative R\&D and firm performance [J]. Research Policy, 2004, 33(10):1477-1492.

[11] Tom Poot, Dries Faems, Wim Vanhaverbeke. Toward a dynamic perspective on open innovation: a longitudinal assessment of the adoption of internal and external innovation strategies in the netherlands. International Journal of Innovation Management, 2013,13(2), 297-322.

[12] Nieto M J, Santamaría L. Technological Collaboration: Bridging the Innovation Gap between Small and Large Firms [J]. Journal of Small Business Management, 2010, 48(1):44-69.

[13] Zahra S A, George G. Absorptive Capacity: A Review, Reconceptualization, and Extension [J]. Academy of Management Review, 2002, 27(2):185-203.

[14] Lane P J, Koka B R, Pathak S. the reification of absorptive capacity [J]. Academy of Management Review, 2006, 31(31):833-863.

[15] Lichtenthaler U. Absorptive Capacity, Environmental Turbulence, and the Complementarity of Organizational Learning Processes [J]. Academy of Management Journal, 2009, 56(6):1830-1830.

[16] Jansen J J P, Volberda H W. Managing Potential and Realized Absorptive Capacity: How Do Organizational Antecedents Matter [J]. Academy of Management Journal, 2005, 48(6): 999-1015.

[17] He Binbin, Liu Qin, Lv Zhengchao, et al. Study of university- firm cooperation, enterprise 
environment and knowledge transfer performance: a case of Yangtze river delta medical devices industry[J]. Mathematical Theory and Applications, 2013(2): 66-74. 